\title{
Prevalence, perception and factors associated with diabetes mellitus among the adult population in central Vietnam: a population-based, cross-sectional seroepidemiological survey
}

Masami Miyakawa ${ }^{1 *}$ (D), Takayuki Shimizu', Nguyen Van Dat ${ }^{2}$, Phung Thanh², Pham Thi Phuong Thuy², Nguyen Thi Hoang $\mathrm{Anh}^{3}$, Nguyen Huu Chau ${ }^{3}$, Yumi Matsushita ${ }^{4}$, Hiroshi Kajio ${ }^{5}$, Vien Quang Mai ${ }^{2}$ and Masahiko Hachiya ${ }^{1}$

\begin{abstract}
Background: Diabetes Mellitus (DM) has rapidly become a major public health concern in Vietnam. Although the prevalence of DM has been studied in northern and southern Vietnam, little data are available for the central region. Therefore, the aims of this survey were to estimate the prevalence of DM and to identify the perception of and factors associated with DM among the adult population in central Vietnam.

Methods: We conducted a cross-sectional, population-based survey in Khánh Hòa Province, Vietnam in December 2014 using three-stage cluster sampling and probability proportional to size sampling in line with the World Health Organization STEPwise approach. Four hundred and eighty residents aged 20-70 years were selected from 30 villages in 10 wards/communes. After obtaining informed consent, all residents participated in interviews regarding lifestyle, medical history, and perception of DM and underwent physical measurements and blood examination for fasting blood glucose and glycated hemoglobin. Factors associated with DM were analyzed using a logistic regression model.
\end{abstract}

Results: A total of 376 residents were enrolled (response rate: 78.3\%; females: 59\%; rural residents: 61\%). Among the participants, $14.3 \%$ and $18.9 \%$ of males and females, respectively, were classified as overweight/obese according to body mass index (BMI), 37.7\% and 22.1\%, respectively, had hypertension, and $36.4 \%$ and $11.7 \%$ had metabolic syndrome. The prevalence of DM in the entire population was 7.2\% (27/376; 95\% confidence interval [Cl]: 4.6-9.8). Participants aged 60-70 years were more likely to have DM than those aged 30-39 years (adjusted odds ratio [aOR]: 8.7; 95\%Cl: 1.4-56.0), and participants classified as obese were more likely to have DM than those with normal or low BMI (aOR: 10.2; 95\%Cl: 2.2-50.2). Furthermore, more than two-thirds (254/376, 67.6\%) of the participants either did not understand or had never heard of DM, and less than half of the DM cases $(12 / 27,44 \%)$ were aware of their history of DM.

Conclusions: The results of this study suggested that the prevalence of DM among the adult population in central Vietnam was slightly higher than that in other areas. Additional research is needed to further explore perceptions of and practices regarding DM.

Keywords: Diabetes mellitus, Central Vietnam, Prevalence, Perception

\footnotetext{
* Correspondence: masami5008@gmail.com

1 Bureau of International Health Cooperation, National Center for Global

Health and Medicine, 1-21-1, Toyama Shinjuku-ku, Tokyo, Japan

Full list of author information is available at the end of the article
} 


\section{Background}

Diabetes mellitus (DM) is a major noncommunicable disease that has rapidly become a major public health concern around the world. In 2014, the number of the adult population with DM had increased to 422 million (prevalence: $8.5 \%$ ), with a particularly sharp rise in middle- and low-income countries. DM was the direct cause of 1.5 million deaths in 2012 [1,2] and is projected to be the seventh leading cause of death by 2030 [3].

In Vietnam in 2015, 3.5 million adults aged 2079 years were estimated to have had DM, 1.8 million of whom remaining undiagnosed; in addition, DM was responsible for 53,400 deaths [4]. Recent studies have reported that the prevalence of DM in the adult Vietnamese population from 2004 to 2016 was $3.7-6.0 \%$ (95\% confidence interval [CI]: 2.7-6.7\%), with 4.7-10.8\% for males and $5.0-11.7 \%$ for females [4-9].

The following factors have also been reported as being associated with DM in Vietnam: classification as being overweight/obese according to body mass index (BMI) in 11.1-19.5\% of males and $14.1-28.3 \%$ of females [5, 10], hypertension in $27.3 \%$ of males and $16.2 \%$ of females [10], and metabolic syndrome in $13.9 \%$ of males and $18.5 \%$ of females [11].

In addition, the following have been identified as risk factors for DM in other studies in Vietnam: being female, older, or overweight/obese, having hypertension or a familial history of DM, engaging in light physical activity, or living in an urban area [6-9].

Other studies reported that $40-73 \%$ of the cases had been unaware that they had DM [7, 9].

Although the prevalence of DM has been studied in northern and southern Vietnam, as described above, little data are available for the central region. Therefore, we conducted a survey in this region to estimate the prevalence of DM and to identify the perception of and factors associated with DM in central Vietnam.

\section{Methods \\ Setting}

We conducted a cross-sectional, population-based seroprevalence survey in Khánh Hòa Province, which is in the south-central coastal region of Vietnam, in December 2014 using three-stage cluster sampling. This province covers an area of $5217.7 \mathrm{~km}^{2}$ and had a population of nearly 1.2 million as of 2014 [12]. The primary economic sectors of this province are industry, construction, and services-tourism [13], and according to official provincial documents $56 \%$ of the communities are rural.

\section{Subjects and sampling methods}

We targeted adult residents of Khánh Hòa Province aged 20-70 years; pregnant women or those who had given birth within the previous 3 months were excluded in order to avoid misclassification due to the likelihood of unstable glycosylated hemoglobin (HbA1c) levels caused by gestational DM.

The required sample size was 426.8 as determined using the equation $\mathrm{n}=Z^{2} \times p(1-p) D e f f /\left(e^{2} \times R R\right)$ from the sample size calculator [14] provided by the World Health Organization (WHO) STEPwise approach to noncommunicable disease risk factor surveillance (STEPS) [15] with a level of confidence $(Z)$ of 1.96 for a $95 \% \mathrm{CI}$, an estimated prevalence of DM $(p)$ of 0.05 , a design effect (Deff) of 2.0, a margin of error $(e)$ of 0.03 , and an expected response rate $(R R)$ of 0.95 . A total of 480 subjects were randomly selected from the population and residents lists from the province using probability proportional to size (PPS) sampling as follows: 10 out of 137 wards/communes, three villages from each ward/commune, and 16 adult inhabitants from each village.

\section{Case definitions}

Blood was collected after at least $8 \mathrm{~h}$ of fasting, as instructed in invitation letters to the participants. Those who met any of the following criteria were consider to have DM [16]: 1) elevated HbA1c level $\geq 6.5 \%$; 2) elevated fasting plasma glucose (FPG) level $\geq 7.0 \mathrm{mmol} /$ L $(126 \mathrm{mg} / \mathrm{dL})$ or random elevated plasma glucose level $\geq 11.1 \mathrm{mmol} / \mathrm{L}(200 \mathrm{mg} / \mathrm{dL})$; or 3$)$ history of treatment for DM (lifestyle guidance including diet or exercise advice, oral medication, or insulin). Those with a marked discrepancy between HbA1c and FPG levels without factors related with DM who were strongly suspected as having hemoglobinopathy were excluded based on clinical grounds.

Residential areas were categorized as either rural or urban based on government classifications. Monthly household income was converted according to the rates in December 2014 (1,000,000 VND = 47.3 USD) [17]. BMI was calculated as body weight $(\mathrm{kg})$ divided by the square of height $\left(\mathrm{m}^{2}\right)$, and then classified as follows: overweight as $\geq 25 \mathrm{~kg} / \mathrm{m}^{2}$ and $<30 \mathrm{~kg} / \mathrm{m}^{2}$, and obese as $\geq 30 \mathrm{~kg} / \mathrm{m}^{2}$ [18]. Hypertension was defined as elevated blood pressure (BP), with systolic BP $\geq 140 \mathrm{mmHg}$ and/or diastolic $\mathrm{BP} \geq 90 \mathrm{mmHg}$ [19]. Hyperlipidemia was determined as the existence of any of the following factors: 1) high total cholesterol (TC) level as $\geq 6.2 \mathrm{mmol} / \mathrm{L}(240 \mathrm{mg} / \mathrm{dL})$ from a multi-country study [20]; 2) low high-density lipoprotein cholesterol (HDL-C) level as $<1.0 \mathrm{mmol} / \mathrm{L}(40 \mathrm{mg} / \mathrm{dL})$; and 3) high triglyceride level as $\geq 2.3 \mathrm{mmol} / \mathrm{L}$ (200 $\mathrm{mg} / \mathrm{dL})$ based on the definition of the laboratory institute. Metabolic syndrome was defined as the existence of any three of the following five factors: 1 ) waist circumference $\geq 90 \mathrm{~cm}$ for males or $\geq 80 \mathrm{~cm}$ for females in the Asian population; 2) triglyceride level $\geq 1.7 \mathrm{mmol} / \mathrm{L}(150 \mathrm{mg} / \mathrm{dL})$; 3) HDL-C level $<1.0 \mathrm{mmol} / \mathrm{L}(40 \mathrm{mg} / \mathrm{dL})$ for males and $<1.3 \mathrm{mmol} /$ $\mathrm{L}$ (50 mg/dL) for females; 4) systolic $\mathrm{BP} \geq 130 \mathrm{mmHg}$ 
and/or diastolic BP $\geq 85 \mathrm{mmHg}$; and 5) FPG level $\geq 5.6 \mathrm{mmol} / \mathrm{L}(100 \mathrm{mg} / \mathrm{dL})$ or drug treatment for elevated glucose level [21].

\section{Perception and self-reported history of DM in Khanh Hoa, Vietnam}

We also explored the perception of DM using structured questionnaires by asking whether they had heard of it or not, moreover whether they understood what DM was if they had heard of it before. Likewise we asked their recognition of current and/or past history of high blood sugar values or DM to let them choose one among yes, no, or unknown. These answers were self-reported and their actual knowledge regarding DM were not verified, while the status of DM in each subject were determined in this study the results of which were tabulated.

\section{Survey process}

The survey process and procedures were carried out in reference to STEPS [15].

Two survey teams composed of researchers or medical and paramedical officers from the Nha Trang Pasteur Institute (IPN) and the Endocrinology Center of Khánh Hòa Provincial Health Service were employed, with three supervisors and nine surveyors deployed to each team. A 2-day training session on the survey process, including questionnaire pretesting, was conducted prior to the survey. General information regarding the survey was sent in an announcement letter to the participants, accompanied by instructions to fast for at least $8 \mathrm{~h}$ before blood tests.

The survey was conducted at 10 commune health centers $(\mathrm{CHCs})$ over a 6-day period. Participants living in the three villages in each catchment area were invited to their respective $\mathrm{CHCs}$ at dawn, and the survey process was conducted throughout the early morning. Laboratory tests and data entry were then carried out in the afternoon every day at the IPN.

After obtaining written informed consent, interviews were conducted using a structured questionnaire, BP and anthropometric measurements were taken, and blood sampling was performed. The structured questionnaire was composed of closed questions with regard to sociodemographic profiles, lifestyle activities, history and perception of DM, and time of last food intake to assure proper fasting prior to testing for FPG. Anthropometric measurements included height, weight, and waist and hip circumference. Venous blood samples $(5 \mathrm{~mL})$ were drawn from each participant by experienced nurses or lab technicians and collected into ethylenediaminetetraacetic acid (EDTA) or plain blood tubes. The EDTA tubes were stored in special blood containers (CubeCooler, Forte Grow Medical Co., Ltd., Tochigi, Japan) at $0-5{ }^{\circ} \mathrm{C}$. Blood in plain tubes was centrifuged at $3000 \mathrm{rpm}$ for 15 min within 30 min after sampling, and supernatant serum was then transferred into microtubes stored on ice to prevent degradation of glucose levels. Finally, all questionnaires were checked by supervisors to ensure that all required answers were appropriately marked.

\section{Blood tests}

Blood samples processed in each $\mathrm{CHC}$ were transported to the IPN within about $6 \mathrm{~h}$ after sampling and tested for HbA1c, glucose, TC, HDL-C and triglycerides. HbA1c was quantified using high-performance liquid chromatography (HPLC; HLC-723 G8; TOSOH, Tokyo, Japan). Glucose, TC, HDL-C and triglycerides were measured in serum. The type of DM among those determined to have DM in this study were not differentiated by further detailed investigation.

\section{Statistical analysis}

All data were validated using double-entry methods and data cleaning, and then analyzed using STATA IC 11 (Stata Corp., College Station, TX, USA) in accordance with the case definitions as indicated above. The characteristics of the enrolled participants were tabulated, and the proportions of those who had DM were calculated using point estimation with $95 \%$ CIs. Odds ratios (ORs) and adjusted ORs (aORs) of having DM $(95 \% \mathrm{CI})$ were estimated in univariate and multivariate analysis using a logistic regression model. The association was regarded as being statistically significant when the $95 \% \mathrm{CI}$ did not contain the value 1.0.

\section{Ethical considerations}

This study was approved by the Institutional Review Boards of the National Center for Global Health and Medicine (NCGM-G-001644-00) in Japan and the IPN. In addition, the protocol and operation of this survey were authorized by the Khánh Hòa Province People's Committee and the Provincial Health Department. Informed consent was obtained in writing or by thumbprint from all participants. All personal information was kept confidential. The notice of results included advice for medical consultations at $\mathrm{CHCs}$ or other health facilities if any abnormal findings were found, and the $\mathrm{CHCs}$ involved in this study were expected to follow-up the participants accordingly.

\section{Results}

\section{Characteristics of the participants}

As shown in Table 1, 376 of the 480 participants were finally enrolled (response rate: 78.3\%). The reasons for failed enrollment included moving out of the study area or refusing to participate. Females accounted for 59.0\% of the participants, and the mean age \pm standard 
Table 1 Characteristics of and prevalence of diabetes mellitus among the enrolled participants in Khanh Hoa, Vietnam

\begin{tabular}{|c|c|c|c|c|c|}
\hline \multirow[t]{3}{*}{ Factor } & \multirow[t]{3}{*}{ Category } & \multicolumn{2}{|l|}{ Males } & \multicolumn{2}{|l|}{ Females } \\
\hline & & \multicolumn{2}{|l|}{$(n=154)$} & \multicolumn{2}{|l|}{$(n=222)$} \\
\hline & & Total n (\%) & $\mathrm{DM}^{\mathrm{a}} \mathrm{n}(\%)$ & Total n (\%) & $\mathrm{DM}^{\mathrm{a}} \mathrm{n}(\%)$ \\
\hline Total & & $154(41.0)$ & $11(7.1)$ & $222(59.0)$ & $16(7.2)$ \\
\hline \multirow[t]{5}{*}{ Age (years old) } & $20-29$ & $36(23.4)$ & $0(0.0)$ & $36(16.4)$ & $0(0.0)$ \\
\hline & $30-39$ & $32(20.8)$ & $1(3.1)$ & $52(23.6)$ & $1(1.9)$ \\
\hline & $40-49$ & $33(21.4)$ & $3(9.1)$ & $57(25.9)$ & $4(7.0)$ \\
\hline & $50-59$ & $39(25.3)$ & $5(12.8)$ & $51(23.2)$ & $4(7.8)$ \\
\hline & $60-70$ & $14(9.1)$ & $2(14.3)$ & $24(10.9)$ & $6(25)$ \\
\hline \multirow[t]{2}{*}{ Residential area } & Rural & $103(66.9)$ & $3(2.9)$ & $128(57.7)$ & $6(4.7)$ \\
\hline & Urban & $51(33.1)$ & $8(15.7)$ & $94(42.3)$ & $10(10.6)$ \\
\hline \multirow[t]{6}{*}{ Occupation } & Manual worker & $86(55.8)$ & $2(2.3)$ & $67(30.2)$ & $4(6)$ \\
\hline & Office worker & $16(10.4)$ & $2(12.5)$ & $23(10.4)$ & $1(4.4)$ \\
\hline & Service worker & $20(13)$ & $5(25)$ & $41(18.5)$ & $1(2.4)$ \\
\hline & Homemaker, Student, No job & $9(5.8)$ & $0(0)$ & $69(31.1)$ & $6(8.7)$ \\
\hline & Retired & $9(5.8)$ & $1(11.1)$ & $10(4.5)$ & $3(30)$ \\
\hline & Others & $14(9.1)$ & $1(7.1)$ & $12(5.4)$ & $1(8.3)$ \\
\hline \multirow[t]{3}{*}{ Marital status } & Never married & $32(20.8)$ & $0(0.0)$ & $12(5.4)$ & $0(0.0)$ \\
\hline & Currently married & $122(79.2)$ & $11(9.0)$ & $187(84.2)$ & $2(6.4)$ \\
\hline & Divorced/widowed & $0(0)$ & $0(0)$ & $23(10.4)$ & $4(17.4)$ \\
\hline \multirow[t]{4}{*}{ Educational level completed } & No school - primary school uncompleted & $18(11.7)$ & $0(0)$ & $45(20.3)$ & $1(2.2)$ \\
\hline & Primary school & $40(26.0)$ & $1(2.5)$ & $69(31.1)$ & $5(7.3)$ \\
\hline & Lower secondary school & $40(26.0)$ & $0(0)$ & $58(26.1)$ & $6(10.3)$ \\
\hline & Higher secondary school - university & $56(36.4)$ & $10(17.9)$ & $50(22.5)$ & $4(8.0)$ \\
\hline \multirow[t]{4}{*}{ Monthly household income (USD $\left.{ }^{b}\right)$} & $<71$ & $19(12.3)$ & $0(0)$ & $38(17.1)$ & $4(10.5)$ \\
\hline & $71-141$ & $35(22.7)$ & $3(8.6)$ & $52(23.4)$ & $4(7.7)$ \\
\hline & $142-283$ & $53(34.4)$ & $3(5.7)$ & $70(31.5)$ & $4(5.7)$ \\
\hline & $\geq 284$ & $47(30.5)$ & $5(10.6)$ & $62(27.9)$ & $4(6.5)$ \\
\hline \multirow[t]{2}{*}{ Level of daily physical activity } & Heavy & $98(63.6)$ & $3(3.1)$ & $78(35.1)$ & $4(5.1)$ \\
\hline & Light & $56(36.4)$ & $8(14.3)$ & $144(64.9)$ & $12(8.3)$ \\
\hline \multirow[t]{3}{*}{ Smoking status } & Never smoker & $31(20.1)$ & $2(6.5)$ & $211(95.1)$ & $16(7.6)$ \\
\hline & Ex-smoker (currently not smoking) & $31(20.1)$ & $3(9.7)$ & $10(4.5)$ & $0(0)$ \\
\hline & Current smoker & $92(59.7)$ & $6(6.5)$ & $1(0.5)$ & $0(0)$ \\
\hline \multirow[t]{3}{*}{ Alcohol consumption } & $<1$ day per week - never consumed & $83(53.9)$ & $6(7.2)$ & $218(98.2)$ & $16(7.3)$ \\
\hline & 1-3 days per week & $50(32.5)$ & $5(10)$ & $3(1.4)$ & $0(0)$ \\
\hline & 4-7 days per week & $21(13.6)$ & $0(0)$ & $1(0.5)$ & $0(0)$ \\
\hline \multirow[t]{3}{*}{$\mathrm{BMI}^{\mathrm{C}}$} & Low or normal & $132(85.7)$ & $7(5.3)$ & $180(81.1)$ & $9(5.0)$ \\
\hline & Overweight & 19 (12.3) & $3(15.8)$ & $34(15.3)$ & $4(11.8)$ \\
\hline & Obesity & $3(2.0)$ & $1(33.3)$ & $8(3.6)$ & $3(37.5)$ \\
\hline \multirow[t]{2}{*}{ Hypertension ${ }^{d}$} & No & $96(62.3)$ & $3(3.1)$ & $173(77.9)$ & $8(4.6)$ \\
\hline & Yes & $58(37.7)$ & $8(13.8)$ & $(22.1)$ & $8(16.3)$ \\
\hline Hyperlipidemia $^{e}$ & No & $127(82.5)$ & $6(4.7)$ & $190(85.6)$ & $13(6.8)$ \\
\hline
\end{tabular}


Table 1 Characteristics of and prevalence of diabetes mellitus among the enrolled participants in Khanh Hoa, Vietnam (Continued)

\begin{tabular}{llllll}
\hline & Yes & $27(17.5)$ & $5(18.5)$ & $32(14.4)$ & $3(9.4)$ \\
Metabolic syndrome $^{f}$ & No & $98(63.6)$ & $2(2.0)$ & $196(88.3)$ & $8(4.1)$ \\
& Yes & $56(36.4)$ & $9(16.1)$ & $26(11.7)$ & $8(30.8)$ \\
\hline
\end{tabular}

${ }^{\mathrm{a} D M}$, Diabetes mellitus. Any of the following factors: 1) elevated HbA1c level $\geq 6.5 \% ; 2$ ) elevated fasting plasma glucose (FPG) level $\geq 7.0 \mathrm{mmol} / \mathrm{L}$ or random elevated plasma glucose level $\geq 11.1 \mathrm{mmol} / \mathrm{L}$; or 3) history of treatment for DM.

${ }^{\mathrm{b}}$ Converted according to the rates in December $2014(1,000,000$ VND $=47.3$ USD).

${ }^{C} \mathrm{BMI}$, Body mass index. Overweight (BMI $\geq 25 \mathrm{~kg} / \mathrm{m}^{2}$ and $\left.<30 \mathrm{~kg} / \mathrm{m}^{2}\right)$, and obese $\left(\mathrm{BMI} \geq 30 \mathrm{~kg} / \mathrm{m}^{2}\right)$.

dRaised blood pressure (BP): systolic BP $\geq 140 \mathrm{mmHg}$ and/or diastolic $\mathrm{BP} \geq 90 \mathrm{mmHg}$.

${ }^{\mathrm{e}}$ Any of the following factors: 1)High total cholesterol (TC) level as $\geq 6.2 \mathrm{mmol} / \mathrm{L} ; 2$ ) low high-density lipoprotein cholesterol (HDL-C) level as $<1.0 \mathrm{mmol} / \mathrm{L} ;$ and 3 ) high triglyceride level as $\geq 2.3 \mathrm{mmol} / \mathrm{L}$.

${ }^{f}$ Any three of the following five factors: 1) waist circumference $\geq 90 \mathrm{~cm}$ for males or $\geq 80 \mathrm{~cm}$ for females in the Asian population; 2) triglyceride level $\geq 1.7 \mathrm{mmol} / \mathrm{L}$; 3) $\mathrm{HDL}-\mathrm{C}$ level $<1.0 \mathrm{mmol} / \mathrm{L}$ for males and $<1.3 \mathrm{mmol} / \mathrm{L}$ for females; 4) systolic BP $\geq 130 \mathrm{mmHg}$ and/or diastolic BP $\geq 85 \mathrm{mmHg}$; and 5) FPG level $\geq 5.6 \mathrm{mmol} / \mathrm{L}$ or drug treatment for elevated glucose level.

deviation was $42.9 \pm 12.7$ years. Rural residents accounted for $61.4 \%$ of the participants and tended to be younger than urban residents. More than half of the males were manual workers, with more than 60\% engaging in heavy physical activity. Regarding females, three in 10 were homemakers or unemployed, with more than $60 \%$ engaging in light activity. Nearly $80 \%$ of males were current or past smokers and 13\% drank alcohol more than 4 days per week. By contrast, only a small proportion of females engaged in such behaviors. Among the participants, $14.3 \%$ and $18.9 \%$ of males and females, respectively, were classified as overweight/obese according to BMI, $37.7 \%$ and $22.1 \%$ as having hypertension, and $36.4 \%$ and $11.7 \%$ as having metabolic syndrome.

\section{Prevalence of DM}

Among the 376 participants, 27 were identified as having DM, which accounted for $7.2 \%$ (95\%CI: 4.6-9.8) of the sample, with $7.1 \%(3.0-11.3)$ for males and $7.2 \%$ (3.810.6) for females. These 27 cases met the criteria for DM, as defined above, as follows: 1) elevated HbA1c level $(18 / 376,4.8 \%) ; 2$ ) elevated FPG level or random elevated plasma glucose level (14/376, 4.0\%); and 3) presence of history of treatment for DM (10/376, 2.7\%). One case with suspected hemoglobinopathy with extremely high HbA1c level (14.1\%) and normal FPG level (4.9 mmol/L) was excluded.

\section{Risk factors associated with DM and other related conditions}

Multivariate analysis identified that those aged 6070 years (aOR: 8.7; 95\%CI: 1.4-56.0) and those being classified as obese according to BMI (aOR: 10.2; 95\%CI: 2.2-50.2) were at a higher risk for DM than those aged 30-39 years and those classified as having low or normal BMI, respectively (Table 2).

\section{Perception and self-reported history of DM}

More than two-thirds $(254 / 376,67.6 \%)$ of the participants either did not understand or had never heard of DM, and less than half of the DM cases $(12 / 27,44 \%)$ had been aware of or reported their history of DM (Table 3).

\section{Discussion}

This study yielded the following three main findings: the prevalence of DM among the adult population in central Vietnam was 7.2\% (95\% CI: 4.6-9.8), being of older age and classified as obese according to BMI were risk factors associated with DM, and residents in central Vietnam had limited awareness of DM.

The prevalence of DM among the adult population in Khánh Hòa Province was slightly higher than national estimates or findings from other studies in northern and southern areas (3.7-6.0\% (95\%CI: $2.7-6.7 \%)$ [4-9]. The prevalence of overweight/obesity according to BMI was compatible with findings from other studies $[5,10]$, while those of hypertension for both sexes and metabolic syndrome for males were far higher in this study compared to others $[10,11]$. The reasons for these discrepancies remain unknown, but because such potentially crucial health issues could be worrisome, these findings require further investigation.

Being older and classified as obese according to BMI were found to be risk factors for DM, which is consistent with findings from other studies in Vietnam [6-9]. The confidence interval of aOR in multivariate analysis in those aged 60-70 and being obese defined by BMI as associated factors with DM widely ranged. One primary reason for it here would be the smaller sample size, while it could be possibly affected by individual variation in impaired level of glucose tolerance due to resistance or impaired secretion of insulin with age or obesity.

More than two-thirds of the participants either did not understand or had never heard of DM, and less than half had been aware of or reported their history of DM. This finding suggests that advocacy and education regarding preventive measures for DM are required to encourage behavioral change for reducing risk factors and promoting the seeking of medical assistance when necessary, as well as consolidation of the health system to ensure 
Table 2 Risk factors associated with diabetes mellitus in Khanh Hoa, Vietnam

\begin{tabular}{|c|c|c|c|}
\hline \multirow[t]{2}{*}{ Factor } & \multirow[t]{2}{*}{ Category } & \multirow{2}{*}{$\begin{array}{l}\text { Univariate analysis }(n=376) \\
\text { OR }(95 \% C l)^{a}\end{array}$} & \multirow{2}{*}{$\begin{array}{l}\text { Multivariate analysis }(n=302) \\
\text { aOR }(95 \% \mathrm{Cl})^{\mathrm{a}}\end{array}$} \\
\hline & & & \\
\hline \multirow[t]{2}{*}{ Sex } & Female & ref. & ref. \\
\hline & Male & $1.0(0.5-2.2)$ & $1.3(0.3-6.8)$ \\
\hline \multirow[t]{5}{*}{ Age (years old) } & $20-29$ & - b & $-\mathrm{b}$ \\
\hline & $30-39$ & ref. & ref. \\
\hline & $40-49$ & $3.5(0.7-17.1)$ & $2.8(0.5-15.3)$ \\
\hline & $50-59$ & $4.6(0.95-21.7)$ & $3.5(0.7-18.7)$ \\
\hline & $60-70$ & $10.9(2.2-54.4)$ & $8.7(1.4-56.0)$ \\
\hline \multirow[t]{2}{*}{ Residential area } & Rural & ref. & ref. \\
\hline & Urban & $3.5(1.4-9.1)$ & $2.6(0.8-7.9)$ \\
\hline \multirow[t]{6}{*}{ Occupation } & Manual worker & ref. & ref. \\
\hline & Office worker & $2.0(0.5-8.6)$ & $1.3(0.2-8.8)$ \\
\hline & Service worker & $2.7(0.8-8.6)$ & $0.6(0.1-3.6)$ \\
\hline & Housekeeper, student, no job & $2.0(0.6-6.6)$ & $0.6(0.1-3.7)$ \\
\hline & Retired & $6.5(1.7-25.8)$ & $0.5(0.1-4.5)$ \\
\hline & Others & $2.0(0.4-10.7)$ & $1.3(0.2-10.1)$ \\
\hline \multirow[t]{2}{*}{ Level of daily physical activity } & Heavy & ref. & ref. \\
\hline & Light & $2.7(1.1-6.5)$ & $2.1(0.5-8.8)$ \\
\hline \multirow[t]{3}{*}{ Smoking status } & Never smoker & ref. & ref. \\
\hline & Ex-smoker (currently not smoking) & $1.0(0.3-3.5)$ & $0.7(0.1-4.5)$ \\
\hline & Current smoker & $0.9(0.3-2.2)$ & $0.7(0.1-4.3)$ \\
\hline \multirow[t]{3}{*}{ BMl } & Low or normal & ref. & ref. \\
\hline & Overweight & $2.8(1.1-7.2)$ & $1.2(0.4-3.7)$ \\
\hline & Obesity & $10.6(2.8-39.9)$ & $10.2(2.2-50.2)$ \\
\hline \multirow[t]{2}{*}{ Hypertension } & No & ref. & ref. \\
\hline & Yes & $4.1(1.7-10.2)$ & $2.0(0.8-5.2)$ \\
\hline \multirow[t]{2}{*}{ Hyperlipidemia } & No & ref. & ref. \\
\hline & Yes & $2.5(1.02-5.9)$ & $2.8(0.9-8.7)$ \\
\hline
\end{tabular}

$O R$ odds ratio, $a O R$ adjusted odds ratio, $C l$ confidence interval, ref. reference, $B M I$, body mass index

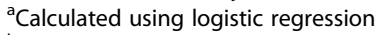

${ }^{\mathrm{b}}$ No cases of DM existed for analysis

Table 3 Perception and self-reported history of diabetes mellitus in Khanh Hoa, Vietnam

\begin{tabular}{|c|c|c|c|}
\hline Factor & Category & Total n (\%) & $\mathrm{DM} n(\%)$ \\
\hline \multirow[t]{4}{*}{ Perception of DM } & & $(N=376)$ & $(N=27)$ \\
\hline & NEVER HEARD of it & $44(11.7)$ & $3(11.1)$ \\
\hline & Ever heard of it but NOT UNDERSTAND what it is & $210(55.9)$ & $11(40.7)$ \\
\hline & Ever heard of it and understand what it is & $122(32.5)$ & $13(48.1)$ \\
\hline \multirow[t]{4}{*}{ Current and/or past history of DM } & & $(N=334)$ & $(N=24)$ \\
\hline & Yes & $36(10.8)$ & $12(50.0)$ \\
\hline & No & $275(82.3)$ & $12(50.0)$ \\
\hline & Unknown & $23(6.9)$ & $0(0.0)$ \\
\hline
\end{tabular}


proper medical care for DM and other noncommunicable diseases.

This study did have several limitations. First, the response rate was lower than expected before the survey (78.3\% vs. 95\%). This lower response rate could have introduced a bias regarding the prevalence of DM, and care should therefore be taken when interpreting the results. Second, under the logistical constraints, HbA1c and FPG were used to diagnose DM instead of the oral glucose tolerance test recommended by the WHO [16]; these tests could be a practical option as a feasible method for detecting DM in seroprevalence surveys in settings with limited resources. Third, hemoglobinopathy, which is a relatively prevalent disorder in Southeast Asia, can compromise the consistency of results for DM diagnosis because it affects HbA1c levels [22, 23]. Therefore, in this study, we excluded one suspected case that demonstrated apparent discordance between HbA1c and FPG levels without laboratory testing for confirmation.

Regardless of these limitations, this population-based study revealed a general epidemiological picture of DM in central Vietnam, and the results are expected to provide insight on affected populations and actions to be prioritized when developing a national program for the prevention of DM. The methods we used in this study also demonstrated good applicability and feasibility of the methods, including PPS sampling or HbA1c for diagnosis of DM, as promising options for future field surveys in resource-limited settings.

\section{Conclusions}

The prevalence of DM among the adult population in central Vietnam was slightly higher than that in other areas of Vietnam. Furthermore, those of an older age and classified as obese according to BMI were found to be at higher risk for DM. Additional studies are needed to further explore perceptions and practices regarding DM in such populations.

\section{Abbreviations}

aOR: Adjusted odds ratio; BMl: Body mass index; BP: Blood pressure; CHCs: Commune health centers; Cl: Confidence interval; DM: Diabetes mellitus; EDTA: Ethylenediaminetetraacetic acid; FPG: Fasting plasma glucose; HbA1c: Glycosylated hemoglobin; HDL-C: High-density lipoprotein cholesterol; HPLC: High-performance liquid chromatography; IPN: Pasteur Institute Nha Trang; NCGM: National Center for Global Health and Medicine; OR: Odds ratio; PPS: Pprobability proportional to size; STEPS: STEPwise approach to noncommunicable disease risk factor surveillance; TC: Total cholesterol; WHO: World Health Organization

\section{Acknowledgments}

We greatly appreciate the Khánh Hòa Provincial Government for their approval, authorization, and substantial cooperation in conducting this survey. We are grateful for the survey teams, CHC staff, and all participants for their valuable contributions to this study. We also thank Ministry of Health of the Socialist Republic of Vietnam for their support, and Dr. Hashimoto for his technical assistance.

\section{Funding}

This work was supported by The Grant for National Center for Global Health and Medicine, Japan (\$26-4). The authors declare that this funding body played no role in the design of the study and collection, analysis, and interpretation of data and in writing the manuscript.

\section{Availability of data and material}

The datasets generated during and/or analyzed during the current study are not publicly available but are available from the corresponding author on reasonable request.

\section{Authors' contribution}

MM designed the study, wrote the proposal, organized and operated the survey, analyzed the data, wrote the manuscript, and edited the final draft for publication. TS conceptualized and designed the study, and wrote the proposal. NVD, PT, and PTPT designed the study, wrote the proposal, organized and operated the survey, and collected the data. NTHA and NHC supervised the survey, YM and HK provided equipment for the survey. VQM designed the study and supervised the whole study process. MH conceptualized and designed the study, wrote the proposal, supervised the whole study process, and edited the final draft for publication. All authors approved the final manuscript of this article prior to submission.

\section{Competing interests}

The authors declare that they have no competing interests.

\section{Consent for publication}

Informed consent was obtained in writing or by thumbprint from all participants.

\section{Ethics approval and consent to participate}

This study was approved by the Institutional Review Boards of National Center for Global Health and Medicine (NCGM-G-001644-00) in Japan and the Nha Trang Pasteur Institute in Vietnam. All participants were fully informed about the study purpose and methods and provided written consent to participate.

\section{Publisher's note}

Springer Nature remains neutral with regard to jurisdictional claims in published maps and institutional affiliations.

\section{Author details}

${ }^{1}$ Bureau of International Health Cooperation, National Center for Global Health and Medicine, 1-21-1, Toyama Shinjuku-ku, Tokyo, Japan. ${ }^{2}$ Pasteur Institute Nha Trang, 8-10 Pasteur, Xuong Huan, tp, Nha Trang, Khánh Hòam, Vietnam. ${ }^{3}$ Endocrinology Center, Khánh Hòa Provincial Public Health Service, 3 A Han Thuyen Street, Nha Trang City, Khánh Hòa Province, Vietnam. ${ }^{4}$ Center for Clinical Sciences, National Center for Global Health and Medicine, 1-21-1, Toyama Shinjuku-ku, Tokyo, Japan. ${ }^{5}$ Department of Diabetes, Endocrinology and Metabolism, Center Hospital, National Center for Global Health and Medicine, 1-21-1, Toyama Shinjuku-ku, Tokyo, Japan.

Received: 14 November 2016 Accepted: 30 March 2017

Published online: 05 April 2017

\section{Reference}

1. World Health Organization. Diabetes Fact sheet. 2016. http://www.who.int/ mediacentre/factsheets/fs312/en/. Accessed 12 Nov 2016.

2. World Health Organization. Global report on diabetes. 2016. http://apps. who.int/iris/bitstream/10665/204871/1/9789241565257_eng.pdf. Accessed 12 Nov 2016.

3. Mathers CD, Loncar D. Projections of global mortality and burden of disease from 2002 to 2030. PLoS Med. 2006;3:e442.

4. International Diabetes Federation. Diabetes in Vietnam - 2015. http://www. idf.org/membership/wp/vietnam. Accessed 12 Nov 2016.

5. World Health Organization. Diabetes country profiles, 2016 - Viet Nam. http://www.who.int/diabetes/country-profiles/vnm_en.pdf?ua=1. Accessed 12 Nov 2016.

6. Pham NM, Eggleston K. Diabetes prevalence and risk factors among Vietnamese adults: findings from community-based screening programs. Diabetes Care. 2015;38:e77-8. 
7. Quang Binh T, Tran Phuong P, Thi Nhung B, Dinh Thoang D, Van Thang P, Khanh Long $T$, et al. Prevalence and correlates of hyperglycemia in a rural population, Vietnam: implications from a cross-sectional study. BMC Public Health. 2012:12:939.

8. Ta MT, Nguyen KT, Nguyen ND, Campbell LV, Nguyen TV. Identification of undiagnosed type 2 diabetes by systolic blood pressure and waist-to-hip ratio. Diabetologia. 2010;53:2139-46.

9. Duc Son LN, Kusama K, Hung NT, Loan TT, Chuyen NV, Kunii D, et al. Prevalence and risk factors for diabetes in ho chi Minh City, Vietnam. Diabet Med. 2004;21:371-6.

10. Pham LH, Au TB, Blizzard L, Truong NB, Schmidt MD, Granger RH, et al. Prevalence of risk factors for non-communicable diseases in the Mekong Delta, Vietnam: results from a STEPS survey. BMC Public Health. 2009;9:291

11. Binh TQ, Phuong PT, Nhung BT, Tung do D. Metabolic syndrome among a middle-aged population in the Red River Delta region of Vietnam. BMC Endocr Disord. 2014;14:77.

12. The people's committee of Khanh Hoa Province. Khanh Hoa Portal. 2016. http://khanhhoa.gov.vn/Default.aspx?Pageld=1815a2fa-69e7-4499-a3a48d92683df0dc. Accessed 12 Nov 2016.

13. Khanh Hoa Department of Tourism. Nha Trang-Khanh Hoa- Viet Nam Tourism, Structure of major economic sectors. 2009. http://nhatrang-travel. com/en/index.php?cat=0203\&type=1\&itemid=18. Accessed 12 Nov 2016.

14. World Health Organization. STEPS Sample Size Calculator and Sampling Spreadsheet. 2016. http://www.who.int/chp/steps/resources/sampling/en/. Accessed 12 Nov 2016

15. World Health Organization. STEPwise approach to noncommunicable disease risk factor surveillance (STEPS). 2016. http://www.who.int/chp/steps/ riskfactor/en/. Accessed 12 Nov 2016.

16. World Health Organization. Definition and diagnosis of diabetes mellitus and intermediate hyperglycemia: Report of a WHO/IDF consultation. 2006. http://www.who.int/diabetes/publications/Definition\%20and\%20 diagnosis\%20of\%20diabetes_new.pdf. Accessed 12 Nov 2016.

17. OANDA. Currency Converter. 2016. https://www.oanda.com/currency/ converter/. Accessed 12 Nov 2016.

18. World Health Organization. Global Database on Body Mass Index, BMI classification. 2016. http://apps.who.int/bmi/index.jsp?introPage=intro_3. html. Accessed 12 Nov 2016

19. Whitworth JA, World Health Organization, International Society of Hypertension Writing Group. 2003 World Health Organization (WHO)/ International Society of Hypertension (ISH) statement on management of hypertension. J Hypertens. 2003;21:1983-92.

20. Roth GA, Finn SD, Mokdad AH, Aekplakorn W, Hasegawa T, Lim SS. High total serum cholesterol, medication coverage and therapeutic control: an analysis of national health examination survey data from eight countries. Bull World Health Organ. 2011;89:92-101.

21. Alberti KG, Eckel RH, Grundy SM, Zimmet PZ, Cleeman II, Donato KA, et al. Harmonizing the metabolic syndrome: a joint interim statement of the International diabetes Federation task force on epidemiology and prevention; National Heart, Lung, and Blood Institute; American Heart Association; world Heart Federation; International atherosclerosis Society; and International Association for the Study of obesity. Circulation. 2009;120:1640-5.

22. World Health Organization. Use of Glycated Haemoglobin ( $\mathrm{HbA} 1 \mathrm{c})$ in the Diagnosis of Diabetes Mellitus, Abbreviated Report of a WHO Consultation. 2011. http://www.who.int/diabetes/publications/report-hba1c_2011.pdf. Accessed 12 Nov 2016

23. Nasir NM, Thevarajah M, Yean CY. Hemoglobin variants detected by hemoglobin $\mathrm{A} 1 \mathrm{c}(\mathrm{HbA} 1 \mathrm{c})$ analysis and the effects on $\mathrm{HbA1c}$ measurements. Int J Diabetes Dev Ctries. 2010;30:86-90

\section{Submit your next manuscript to BioMed Central and we will help you at every step:}

- We accept pre-submission inquiries

- Our selector tool helps you to find the most relevant journal

- We provide round the clock customer support

- Convenient online submission

- Thorough peer review

- Inclusion in PubMed and all major indexing services

- Maximum visibility for your research

Submit your manuscript at www.biomedcentral.com/submit
C) BioMed Central 